\title{
Case Report of Ectopic Pregnancy during Controlled Ovarian Stimulation without Oocytes Harvested and Late Ovarian Hyperstimulation Syndrome
}

\author{
Hui Lin*, Wen He*, Jie Lv, Chanlin Han, Li Sun, Jianping Ou, Liuhong Cai\# \\ Center for Reproductive Medicine, The Third Affiliated Hospital, Sun Yat-sen University, Guangzhou, China \\ Email: "cailh@mail.sysu.edu.cn
}

How to cite this paper: Lin, H., He, W., Lv, J., Han, C.L., Sun, L., Ou, J.P. and Cai, L.H. (2018) Case Report of Ectopic Pregnancy during Controlled Ovarian Stimulation without Oocytes Harvested and Late Ovarian Hyperstimulation Syndrome. Advances in Reproductive Sciences, 6, 102-108.

http://dx.doi.org/10.4236/arsci.2018.63008

Received: June 28, 2018

Accepted: August 14, 2018

Published: August 17, 2018

Copyright $\odot 2018$ by authors and Scientific Research Publishing Inc. This work is licensed under the Creative Commons Attribution International License (CC BY 4.0).

http://creativecommons.org/licenses/by/4.0/

\begin{abstract}
Here we reported a rare case of misdiagnosed ectopic pregnancy (EP) due to unintended ovulation during controlled ovarian stimulation (COS) in GnRH agonist cycle, resulting in no oocytes harvested and late hyper-stimulation syndrome (OHSS). The patient was a 33-year old primary infertile woman due to male's factors and underwent her second in vitro fertilization (IVF) cycle using GnRH agonist protocol, and no oocytes harvested on ovum picked-up (OPU) day. The start of gonadotropin usage was on day $8^{\text {th }}$ of her period, and the $\mathrm{P}$ level increased rapidly and strangely high from day $8^{\text {th }}$ after gonadotropin usage. The $\mathrm{E} 2$ level and follicles grew normally but finally no oocytes harvested. She was diagnosed as late ovarian hyper-stimulation syndrome (OHSS) 7 days after OPU. 20 days after OPU, no menstruation come and a positive urine test of hCG were reported. And the patient was diagnosed as EP by laparoscopy. In conclusion, rapidly increased P level, no oocyte retrieval and late onset of OHSS should be very important clues to diagnose this misdiagnosed EP.
\end{abstract}

\section{Keywords}

In-Vitro Fertilization, Ectopic Pregnancy, Controlled Ovarian Stimulation, Gonadotropin-Releasing Hormone Agonist

\section{Introduction}

Pregnancy diagnosed after down-regulation is common during gonadotro-

*The two authors contributed equally to this manuscript. 
pin-releasing hormone agonist ( $\mathrm{GnRH}-\mathrm{a})$ cycle, but usually before the usage of gonadotropin $(\mathrm{Gn})$, with the approximate prevalence around $0.8 \%$ of all cases [1]. Most of the cases reported so far are diagnosed before initiating ovarian stimulation by some hints such as delayed periods or no periods [2]. But seldom reports about the pregnancy occurred during ovarian stimulation. For those misdiagnosed cases, previous studies agreed that the GnRH-a had no harm to the pregnancy outcome during luteal phase down-regulation [3]. And cases reported that it could extract oocytes and obtain embryos following a superovulation procedure in early pregnant patients [4]. We here report a rare case of ectopic pregnancy (EP) occurred during Gn stimulation due to unintended ovulation, and ended with failure to retrieve any oocytes and onset of late hyper-stimulation syndrome (OHSS).

\section{Case Report}

A 33-year-old woman, gravida 0 , para 0 , with regular menstrual cycle of 28 - 30 days, came to our center for the treatment of primary infertility in August 2015. She had a 4-year history of primary infertility and denied abnormal gynecological, medical, or surgical history. Hormonal profiles in 2017: basal FSH 7.2 $\mathrm{mIU} / \mathrm{ml}(3.5$ - $12.5 \mathrm{mIU} / \mathrm{ml})$, LH $6.8 \mathrm{mIU} / \mathrm{ml}(2.4-12.6 \mathrm{mIU} / \mathrm{ml}) \mathrm{E}_{2} 35 \mathrm{mIU} / \mathrm{ml}$ (26.7 - $156 \mathrm{mIU} / \mathrm{ml})$, prolactin $15.9 \mathrm{ng} / \mathrm{ml}(4.04-15.2 \mathrm{ng} / \mathrm{ml})$, P $0.09 \mathrm{ng} / \mathrm{ml}$ (0.057 - $0.893 \mathrm{ng} / \mathrm{ml})$, and totol testosterone $0.44 \mathrm{ng} / \mathrm{ml}(0.08-0.48 \mathrm{ng} / \mathrm{ml})$. The AMH level was $3.832 \mathrm{ng} / \mathrm{ml}(1.66-9.49 \mathrm{ng} / \mathrm{ml})$. Hysterosalpingography showed no tubal pathology. The sperm parameters of her husband indicated teratozoospermia.

The patient was referred to IVF-ET because of recurrent intra-uterine insemination failures. She underwent her first IVF cycles with GnRH-a long protocol in April 2016, and 11 oocytes were retrieved. A freeze-all approach was applied for 4 cleavage embryos and 1 blastocyst. She underwent 3 times of frozen embryo-transfer and still failed to conceive a baby.

After two normal menstrual cycles, the second IVF-cycle was initiated. On cycle day 20, ovulation was confirmed by transvaginal ultrasound examination and hormonal analyses, and pituitary down-regulation using Decapeptyl $0.1 \mathrm{mg}$ daily (Ferring, Germany) was started. On day 6 of next menses, the endometrial thickness was $10.6 \mathrm{~mm}$ and we did not perform the ovulation stimulation procedure due to her out for work. Two days later, with the P being $0.482 \mathrm{ng} / \mathrm{ml}$ and $\mathrm{E}_{2}$ being $9.64 \mathrm{pg} / \mathrm{ml}$, ovarian stimulation was commenced with a daily dose of $200 \mathrm{IU}$ recombinant FSH (Puregon $200 \mathrm{IU} /$ day, MSD, China) and the dose of triptorelin was reduced to $0.05 \mathrm{mg}$ per day. On the sixth day of stimulation, the $\mathrm{P}$ level increased to $1.77 \mathrm{ng} / \mathrm{ml}$, the $\mathrm{E}_{2}$ level was $861.3 \mathrm{pg} / \mathrm{ml}$, and the leading follicles were around $11 \mathrm{~mm}$ in diameter. Three days later, the P level was 3.57 $\mathrm{ng} / \mathrm{ml}$, the $\mathrm{E}_{2}$ level was $2128 \mathrm{pg} / \mathrm{ml}$, the $\mathrm{LH}$ level reduced to $0.806 \mathrm{IU} / \mathrm{L}$, the leading follicles were around $13 \mathrm{~mm}$ in diameter, and the triptorelin administration was cancelled. On the tenth day of stimulation, the P level increased to 5.99 
$\mathrm{ng} / \mathrm{ml}$, the $\mathrm{E}_{2}$ level slightly increased to $2848 \mathrm{pg} / \mathrm{ml}$, and the leading follicles were around $16 \mathrm{~mm}$ in diameter. Two days later, the P level increased to $19.12 \mathrm{ng} / \mathrm{ml}$, the $\mathrm{E}_{2}$ level was $3218 \mathrm{pg} / \mathrm{ml}, 11$ follicles exceeded $18 \mathrm{~mm}$ in diameter with the largest one being $28 \mathrm{~mm}$; final oocyte maturation was triggered with recombinant hCG (Ovidrel $250 \mu \mathrm{g}$, Merck, Switzerland). At last, no oocytes were harvested. No obvious abnormalities were found in uterine cavity or in bilateral adnexa during COS procedure. The serum levels of $\mathrm{E}_{2}$ and $\mathrm{P}$ during COS were showed in Figure 1.

The patient was diagnosed with late OHSS 7 days after OPU, due to bloating, nausea, ovarian enlargement and ascites. 20 days after OPU, she reported no menstruation. The urine test of hCG showed positive and serum hCG level was $6580 \mathrm{IU} / \mathrm{L}$, but no gestational sac was observed. She was diagnosed ectopic pregnancy (EP) and administered to in-patient department and the diagnosis was confirmed by laparoscopy and pathological reports.

Informed consent has been obtained from the patient.

\section{Discussion}

Early pregnancies during pituitary down-regulation comprise less than $1 \%$ of all IVF cycles with GnRH-a [1] [5]. But this is a misdiagnosed EP due to our improper handling.

EP during pituitary down-regulation is easily to be misdiagnosed. Despite the use of improved diagnostic methods (high-resolution transvaginal sonography and serum measurement of the $\beta$-hCG), it is believed that $40 \%-50 \%$ of ectopic pregnancies are initially misdiagnosed [6]. $\beta$-hCG is detectable 8 days after ovulation or 1 day after implantation, but abnormal gestation may have a fall of

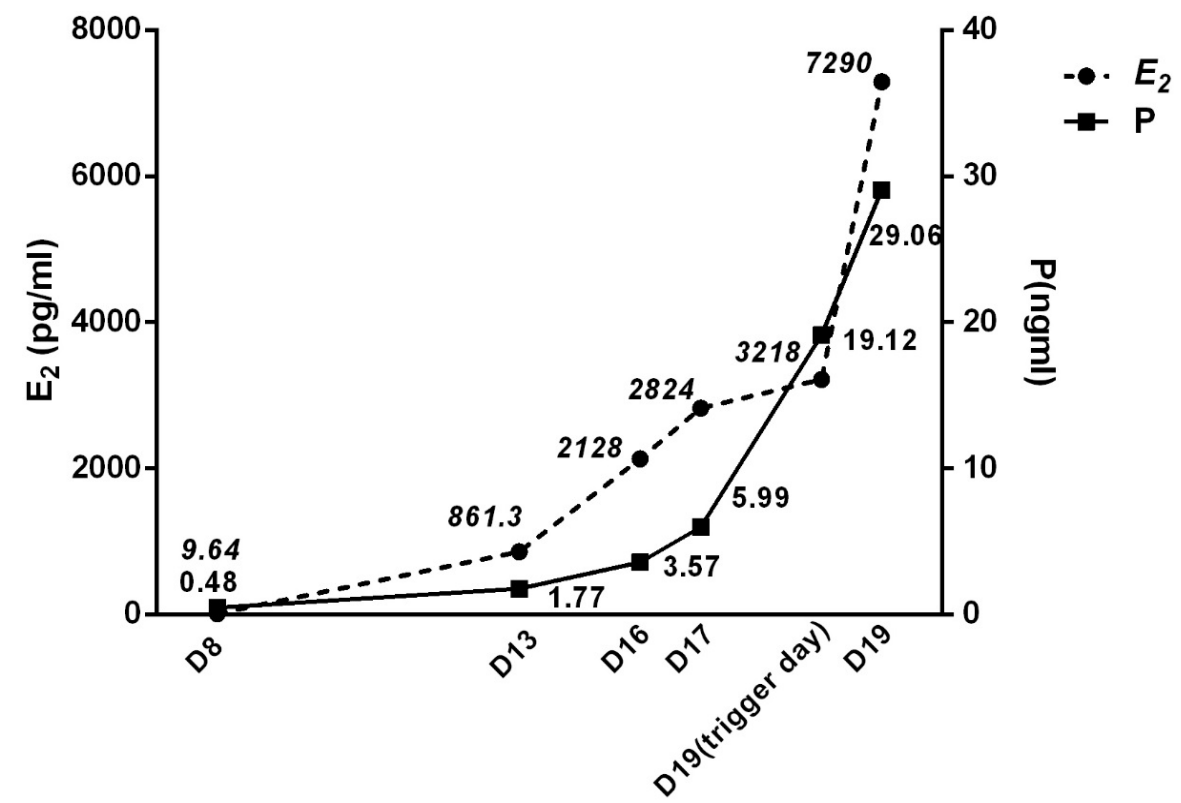

Note: $\mathrm{E} 2$ = estrogen; $\mathrm{P}=$ progesterone. The dates of menstruation are shown on $\mathrm{X}$-axis.

Figure 1. E2 and P levels during the procedure of ovarian stimulation. 
$\beta$-hCG level or a low level of $\beta$-hCG [7] [8]. In addition, previous studies demonstrated that serum $\mathrm{P}$ level, another important hormone supports pregnancy diagnosis, are lower in abnormal gestation [9] [10]. Although there is no consensus about the effect of GnRH-a on corpus luteum function, most studies in human report that GnRH-a can reduce the luteal phase length, especially started in the early luteal phase [11] [12]. All physiopathologic changes mentioned above made the present early EP hard to be diagnosed.

The rising level of $\beta$-hCG caused by EP or uterine pregnancy may affect the follicular development [4] [13] [14]. So far as we know, there were a few cases about stimulation of folliculogenesis in patient concomitant an undiagnosed pregnancy after GnRH-a administration. All these cases suggested that the gonadotropin, whether was exogenous or endogenous induced by clomiphene citrate, can induce follicles to grow to the final mature stage [15] [16]. Nevertheless, the quality and quantity of oocytes in these cases were poor, which might be due to the high serum level of $\beta$-hCG [4].

As for this case, the late start (on day 8) of Gn and regular referral is the reason of unintended ovulation, and we knew ovulation may happen, but unrealized the pregnancy. We observed a normal follicular growth during COS procedure and it was difficult to find out abnormalities by transvaginal ultrasonography (Figure 2). On the contrary, abnormal increased serum levels of $\mathrm{P}$ were recorded (Figure 1). The early rising $\mathrm{P}$ level implied the occurrence of premature luteinization or ovulation in advance. Empty follicle syndrome is a condition in which no oocytes are retrieved after ovulation induction with normal

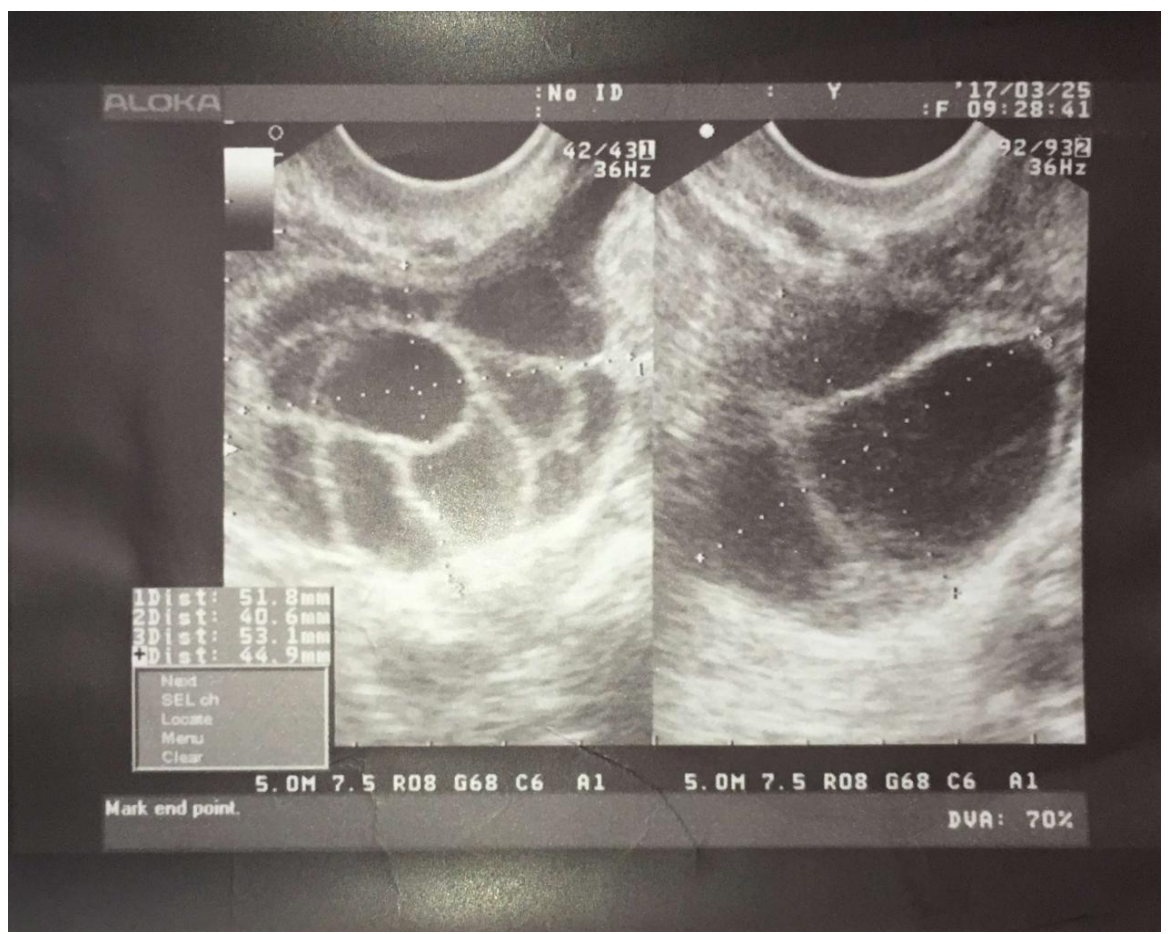

Figure 2. The patient's transvaginal ultrasound revealed a normal ultrasonography of follicular development. 
steroidogenesis for IVF treatment [17]. Late OHSS gave another clue to the pregnancy, which was similar with the late OHSS in fresh embryo-transfer cycle [18]. But again, we missed this chance to diagnose EP at that time. We knew that double stimulations during the follicular and luteal phases are feasible [19]. Based on the low blood $\mathrm{E}$ and P levels on the Gn starting day, we can determine that this patient's pregnancy was due to accidental ovulation during the propulsion. Although both the follicles diameter and E level are growing normally, no eggs were obtained, which is estimated to be related to the long-term effects of HCG during pregnancy.

\section{Conclusion}

Rapidly increased P level, no oocyte retrieval and late onset of OHSS should be very important clues to diagnose EP or pregnancy, no matter how normally growing of follicles diameter or E level.

\section{Funding}

This work was supported by the Department of Science and Technology of Guangdong Province (grant No. 2014A070711008).

\section{Conflicts of Interest}

The authors declare no conflicts of interest regarding the publication of this paper.

\section{Ethic Approval and Consent to Participate}

Approval was obtained from the Reproductive Medicine Ethic Committee, the Third Affiliated Hospital of Sun Yat-sen University for publishing this case report.

\section{References}

[1] Lahat, E., Raziel, A., Friedler, S., Schieber-Kazir, M. and Ron-El, R. (1999) Long-Term Follow-Up of Children Born after Inadvertent Administration of a Gonadotrophin-Releasing Hormone Agonist in Early Pregnancy. Human Reproduction, 14, 2656-2660. https://doi.org/10.1093/humrep/14.10.2656

[2] Young, D.C., Snabes, M.C. and Poindexter, A.N. (1993) GnRH Agonist Exposure during the First Trimester of Pregnancy. Obstetrics \& Gynecology, 81, 587-589.

[3] Platteau, P., Gabbe, M., Famelos, M., Kovacs, G. and Healy, D. (2000) Should We Still Advise Infertile Couples to Use (Barrier) Contraception before IVF Down-Regulation? Fertility and Sterility, 74, 655-659. https://doi.org/10.1016/S0015-0282(00)01524-7

[4] Bayrak, A., Fogle, R.H. and Paulson, R.J. (2008) Clomiphene Citrate-Induced Follicular Development in the Presence of an Ovarian Ectopic Pregnancy. Fertility and Sterility, 89, 456.e451-452. https://doi.org/10.1016/j.fertnstert.2007.03.038

[5] Serafini, P., Yee, B., Vargyas, J. and Marrs, R.P. (1985) Development of Multiple Ovarian Follicles for in Vitro Fertilization in a Patient with an Undiagnosed Ectopic 
Pregnancy. Fertility and Sterility, 43, 656-658.

https://doi.org/10.1016/S0015-0282(16)48513-4

[6] Abbott, J., Emmans, L.S. and Lowenstein, S.R. (1990) Ectopic Pregnancy: Ten Common Pitfalls in Diagnosis. American Journal of Emergency Medicine, 8, 515-522. https://doi.org/10.1016/0735-6757(90)90154-R

[7] Landesman, R. and Saxena, B.B. (1974) Radioreceptorassay of Human Chorionic Gonadotropin as an Aid in Miniabortion. Fertility and Sterility, 25, 1022-1029. https://doi.org/10.1016/S0015-0282(16)40810-1

[8] Sinosich, M.J., Grudzinskas, J.G. and Saunders, D.M. (1985) Placental Proteins in the Diagnosis and Evaluation of the "Elusive" Early Pregnancy. Obstetrical \& $G y$ necological Survey, 40, 273-282. https://doi.org/10.1097/00006254-198505000-00002

[9] Dart, R., Ramanujam, P. and Dart, L. (2002) Progesterone as a Predictor of Ectopic Pregnancy When the Ultrasound Is Indeterminate. American Journal of Emergency Medicine, 20, 575-579. https://doi.org/10.1053/ajem.2002.35460

[10] Perkins, S.L., Al-Ramahi, M. and Claman, P. (2000) Comparison of Serum Progesterone as an Indicator of Pregnancy Nonviability in Spontaneously Pregnant Emergency Room and Infertility Clinic Patient Populations. Fertility and Sterility, 73, 499-504. https://doi.org/10.1016/S0015-0282(99)00543-9

[11] Eley, R.M. (1987) The Effect of LHRH Analogs on Pregnancy in the Baboon. Contraception, 35, 389-393. https://doi.org/10.1016/0010-7824(87)90075-8

[12] Bergquist, C., Nillius, S.J. and Wide, L. (1980) Effects of a Luteinizing Hormone-Releasing Hormone Agonist on Luteal Function in Women. Contraception, 22, 287-293. https://doi.org/10.1016/S0010-7824(80)80007-2

[13] Sharma, V., Riddle, A., Collins, W., Campbell, S. and Mason, B. (1987) Gonadotropin-Induced Successful Follicular Development, Oocyte Recovery, Fertilization, and Cleavage of Embryos in Undiagnosed Early Pregnancy. Journal of in Vitro Fertilization and Embryo Transfer, 4, 61-63. https://doi.org/10.1007/BF01555439

[14] Sammour, A., Biljan, M., Tan, S.L. and Tulandi, T. (2001) A Documented Clomiphene-Induced Follicular Development in Pregnancy. Human Reproduction, 16, 1098-1099. https://doi.org/10.1093/humrep/16.6.1098

[15] Neuwinger, J., Siebzehnrubl, E., Todorow, S., Spitzer, M. and Wildt, L. (1995) Ovarian Stimulation with Gonadotropins in Undetected Tubal Pregnancy within the Scope of in Vitro Fertilization. Geburtshilfe Und Frauenheilkunde, 55, 56-57. https://doi.org/10.1055/s-2007-1022775

[16] Zech, N.H., Netzbandt, P. and Zech, H. (2005) Development of Severe Ovarian Hyperstimulation Syndrome after Inadvertent Stimulation with a Gonadotropin-Releasing Hormone Agonist and Human Menopausal Gonadotropin in a Pre-Existing Early Pregnancy. Fertility and Sterility, 84, 1745.

https://doi.org/10.1016/j.fertnstert.2005.05.069

[17] Snaifer, E., Hugues, J.N., Poncelet, C., Sifer, C., Pasquier, M. and Cedrin-Durnerin, I. (2008) "Empty Follicle Syndrome" after Human Error: Pregnancy Obtained after Repeated Oocyte Retrieval in a Gonadotropin-Releasing Hormone Antagonist Cycle. Fertility and Sterility, 90, 850.e813-855. https://doi.org/10.1016/j.fertnstert.2007.08.008

[18] Delvigne, A. and Rozenberg, S. (2003) Review of Clinical Course and Treatment of Ovarian Hyperstimulation Syndrome (OHSS). Human Reproduction Update, 9 , 77-96. https://doi.org/10.1093/humupd/dmg005 
[19] Kuang, Y., Chen, Q., Hong, Q., Lyu, Q., Ai, A., Fu, Y. and Shoham, Z. (2014) Double Stimulations during the Follicular and Luteal Phases of Poor Responders in IVF/ICSI Programmes (Shanghai Protocol). Reproductive BioMedicine Online, 29, 684-691. https://doi.org/10.1016/j.rbmo.2014.08.009 